\title{
SELETIVIDADE TEENAGER: A SENSIBILDADE EUGÊNICA EM IMAGENS DO HIGH SCHOOL
}


SELETIVIDADE TEENAGER: A SENSIBILDADE EUGÊNICA EM IMAGENS DO HIGH SCHOOL

Resumo: O teenager, enquanto personagem do entretenimento visual midiático, submete-se a um pathos pelo reconhecimento entre seus pares e sofre as consequências de seu contraponto. Nesse artigo, vamos tornar evidente como algumas imagens de teenagers agenciam um tipo de sensibilidade eugênica, ancorando-se na análise do binômio prazer/desprezo visual gerado pelas relações semi-simbólicas de filmes e seriados específicos.

Palavras chave: teenager; popularidade; High School e sensibilidade eugênica

\section{SELECTIVIDAD TEENAGER: LA SENSIBILIDAD EUGENÉSICA EN IMAGENES DE HIGH SCHOOL}

Resumen: El teenager, como personaje del entretenimiento visual mediático, se encuentra bajo el pathos por el reconocimiento entre sus pares y sufre las consecuencias de su contrapunto. En el presente artículo buscamos evidenciar como algunas imágenes de teenagers agencian un tipo de sensibilidad eugénesica, basándose en el análisis del binomio placer/desprecio visual generado por las relaciones semisimbólicas de películas y seriados específicos.

Palabras clave: teenager; popularidad; High School y sensibilidad eugénesica

TEENAGER SELECTIVITY: EUGENIC SENSIBILITY ON HIGH SCHOOL IMAGES

Abstract: The teenager, as a character of visual media entertainment, is subjected to a pathos for the recognition among their peers and suffers the consequences of its counterpoint. In this paper, we draw attention to how some images of teenagers engage a kind of eugenic sensibility, based on the analysis of the binomial pleasure / visual contempt generated by the semi-symbolic relations of specific movies and TV shows.

Key words: teenager; popularity; High School and eugenic sensibility 


\section{INTRODUÇÃO}

As imagens da adolescência e do início da juventude tornaram-se objeto de interesse da indústria midiática do entretenimento especialmente a partir da década de 1950, logo após ter sido forjado o conceito de teenager. O termo passou a ter uso corrente a partir do ano de 1944, por influência de uma publicação americana orientada para o público adolescente chamada Seventeen. A palavra tenta dar conta de uma nova definição do jovem como parte de um mercado de massa identificável (SAVAGE, 2009:484) que não era nem adolescente, nem delinquente, mas um contrapeso entre o didatismo de um termo e a profunda negatividade do outro.

A origem do termo estava na forma flexionada de "ten", dez, que, segundo o Concise Oxford Dictionary, era "acrescentado aos numerais de três a nove para formar os nomes daqueles de 13 a 19. (...) "Teenage tinha sido usado livremente depois de meados dos anos 1930, muitas vezes hifenizado como teen-age, enquanto tentativas para promover alternativas canhestras como "teener" e "teenster" fracassaram. (...) Dar nome a alguma coisa às vezes ajuda a lhe conferir existência: adotado tanto pelos profissionais de marketing para jovens como pelos próprios jovens, o nome teenage era claro, simples e dizia o que significava. Tratava-se da Era - o período distinto social, cultural e economicamente - dos teen. (SAVAGE,2009: 484-485)

De filmes como Juventude Transviada (Rebel Without a Cause, 1955) a seriados televisivos recentes como Gossip Girl (2007-2012) a retratação do teenager parece ilustrar o pathos da cultura midiática em exercer um tipo de seletividade biofísica na imagem. Como observaremos ao longo desse texto, o prazer visual agenciado por várias imagens de teenagers têm uma tendência a gerar um percurso de sentido por meio da valorização cultural de formantes plástico que acirram o binômio seleção/exclusão como a beleza, a fisicalidade potente, a belicosidade e a riqueza ostensiva.

Sob a aparência apolínea, o humor bestial, o colorido pop ou o drama raso de filmes e seriados que acontecem no entorno dos chamados High Schools jaz um desejo inconsciente comprometido ainda pelo projeto estético da modernidade em que apenas os melhores e mais adaptáveis serão capazes de sobreviver ou mesmo 'brilhar' no quadro da imagem.

Assim, esse artigo, sob a forma de um mostruário de diversas imagens sobre 
teenagers, tem como objetivo tornar evidente um dos traços eugênicos mais intensos e ao mesmo tempo mais banalizados no regime de imagens contemporâneo: a cultura visual produzida em torno da juventude. Ao mesmo tempo, nos preocuparemos em apontar a insistente associação entre teen culture e consumismo, em produtos visuais mais recentes, observando o potencial ostensivo do consumismo como modelador de um sentimento de comunidade pura e inacessível.

Não pretendemos seguir, para tanto, um cronograma linear das produções visuais de entretenimento sobre teenagers, mas, a partir de uma relativa aleatoriedade, pincelar e dissecar os detalhes narrativos e pequenos deslizes visuais que os comprometem como agentes para um tipo de seletividade biofísica na imagem.

Desta forma, vamos nos concentrar menos na idealidade objetiva de seus discursos, e mais nas paixões, afetos e enfermidades que caracterizam estas peças do entretenimento visual. O objetivo epistemológico e cognitivo dessa expedição é fazer enxergar no universo aparentemente a-político de filmes e seriados adolescentes a lógica que combina a beleza, a juventude e o senso de coletividade ao ao narcisismo como modo de ser privilegiado na imagem. Vamos nos ater especialmente ao pathos pela dignidade somatizado nesses plots e que é reorganizado segundo uma gramática da popularidade como indício de poder.

\section{A POPULARIDADE COMO FORMA DE DIGNIDADE E BESTIALIZAÇÃO}

A relação ambivalente que as imagens de entretenimento sobre o High School e os teenagers estabelecem com a necessidade de reconhecimento e o consequente desprezo de tudo o que não se submete a um regime de ostensividade da imagem de si diante do olhar do outro apoia-se nos móbiles de um regime de visualidade fetichista e narcisista. Nestes produtos a popularidade como imperativo categórico aponta para a captura do desejo por uma forma de idealização apolínea da vida concebida na tensão entre reconhecimento e desprezo. Eles oferecem um modelo didático para entendermos como o imaginário sobre a juventude vem sendo formatado pela cultura de mídias, e, de forma relativamente discreta, como vem se elaborando uma noção de dignidade que se confunde com idealismo estético excludente, disfarçado sob a aparente bestialidade da imagem.

A questão da popularidade como vem sendo retratada nas projeções visuais sobre esta paisagem da cultura americana pode ser entendida a partir da noção de reconhecimento, tanto através de sua valorização no espaço das lutas cultu- 
rais travadas em plena modernidade, quanto por meio da assunção recente da chamada cultura do narcisismo'. Como veremos, a disseminação do fenômeno da popularidade (popularity) tem a ver com as modificações em torno da noção da visibilidade e ostensividade da imagem de si que aconteceram após a consagração dos meios de comunicação de massa na efetividade da vida social.

Um aspecto que nos interessa especialmente ao investigarmos este imperativo da popularidade no imaginário midiático juvenil é o seu contraponto inconsciente, o da exclusão e da seleção. De forma direta, podemos afirmar que a relação entre a popularidade entre os pares teenagers como um ideal na cultura de entretenimento toca um regime de visualidade que valoriza a fisicalidade, o triunfo e o desejo de poder como questões centrais e em torno do que a ação se resume.

Nos últimos dois séculos, os conceitos de reconhecimento e desprezo acompanharam as conquistas que reorganizaram as relações entre as classes sociais e as formas de visibilidade que estas cooptaram para si desde então na esfera pública. A crescente assunção da burguesia, o surgimento do fenômeno das massas no século XIX e finalmente a concretização dos meios de comunicação de massa no século XX, passaram a articular, por um lado, reconhecimento social à dignidade, e por outro, desprezo à ausência de reconhecimento, mesmo entre classes anteriormente alheias a tais preocupações.

Segundo Peter Sloterdijk (2002) a cultura tornou-se a arena mais profícua para o embate entre as classes e a luta pelo reconhecimento. A modernidade se caracterizaria neste sentido como um momento histórico em que "elite" e "massa" ou "iguais" e "mais iguais" travam uma luta para que se faça justiça aos interesses da maioria possível, formando-se assim uma coletividade que se relacionaria de acordo com dois polos (38): a comunicação vertical (ofender) e a comunicação horizontal (adular). Estes dois polos gravitariam em torno da questão do reconhecimento, que, caso recusado, pode ser entendido como desprezo. $\mathrm{Na}$ concepção espinosiana explorada pelo autor (57) o desprezo é definido como a imaginação de uma coisa que toca tão pouco à mente, que esta, pela presença da coisa, prefere imaginar aquilo que não está na coisa do que aquilo que está ${ }^{2}$.

Essa forma de paixão pela dignidade sofreria transformações substanciais, dadas as condições intelectuais estruturalmente incipientes das massas, as quais, a partir do momento em que adquiriram voz no espaço da esfera pública passa-

1 Ver Lasch, Christopher (1983). A cultura dor narcisismo.

2 Ver Espinosa. Ética, parte II, proposição 49, escólio. 
riam a reivindicar sua entrada nos livros de história e em cerimônias públicas:

Deve-se notar que os grupos em ascensão dos tempos recentes não apenas manifestam um pathos autobiográfico; eles desenvolvem, também sem exceção, um afeto filantrópico, mais exatamente autofilantrópico. Não esqueçamos que também os Estados nacionais do século XIX e XX só puderam tomar forma como experimentos de dignidade coletiva e auto-elevação conduzidos pela mídia de massa - e que a chamada política externa foi sempre necessariamente dramatizada entre essas tensões de atenção e desprezo, contanto que incluíssem concorrências no imaginário. (41)

Nesse campo sensível, a tensão em torno do reconhecimento passa a ser entendida como forma de destacamento, e no outro sentido, o reconhecimento recusado torna-se ofensa, passa a afigurar um embaraço estético e moral irreparável. Assim, afirmamos que o imaginário que se constrói em torno do High School midiático celebra um movimento de bestialização tanto na forma de comunicação que dissemina como primordial entre os teenagers (aduladores versus ofensores) quanto na maneira como retrata o seu engajamento socialmente, conformando-se aos móbiles de um narcisismo de massa em que o popular passa a ser visto como aquele que alcança o reconhecimento e o não-popular como o que padece de desprezo.

Ainda mais importante - seguindo esta lógica de elevação de objetos triviais e pessoas a primeiro plano - é que neste modelo de produto visual, central à paisagem do entretenimento contemporâneo, tudo o que convida à reflexão e à vida espiritual - no sentido que Hannah Arendt (2010) atribui ao termo - é rechaçado como forma de fraqueza, feiura e embaraço.

Em uma diversidade de filmes e seriados sobre teenagers a condição da irreflexão ou a da inocuidade do pensamento é sensibilizada como um modo de ser esteticamente privilegiado que se reflete na própria composição da imagem. Lindas mulheres ou jovens rapazes atléticos são cercados por elementos representacionais ou não representacionais (como outros personagens, cenário, música, câmera lenta ou close) que exaltam ainda mais a sua beleza como um signo do poder entre seus pares. Lembremos de protagonistas como Cher Horowitz (As patricinhas de Bervely Hills, 1995) e Serena Van der Woodsen (Gossip Girl, 2007-2012) ou antagonistas como Regina George (Meninas Malvadas, 2004) ou Kelly Taylor (na primeira temporada de Barrados no Baile, 1990): personagens femininas que agenciam o prazer visual da beleza de forma direta- 
mente associada a sua tolice, ingenuidade ou trivialidade.

A beleza física como explorada pela formação da imagem repousa sobre aqueles que ilustram com mais veemência a cultura anti-intelectual e anti-espiritual. O que faz sentido, se levarmos em conta a idéia arendtiana de que a principal característica da vida espiritual é a sua invisibilidade (2010:90). O "viver oculto", o voltar-se para a reflexão, como o exercício minimamente filosófico que não apenas é desinteressante à idéia de entretenimento midiático, mas, torna-se, na imagem divertida do High School, um objeto de ridicularização e mesmo desprezo: o oposto do intelecto é a felicidade da diluição e reconhecimento na (cultura) de massa. A retratação do teenager, como personagem imagético inovador no século $X X$, parece levar isso mais a sério que outros. Ela invoca a fórmula fascista da apatia espiritual como modo de comunicação com alto risco de invocação do reacionário, do conservador e da supremacia da identidade em detrimento da diferença.

Tais vetores da bestialização compõem os traços para uma cultura que se abastece da própria inércia do pensamento e dos riscos inerentes a este fenômeno: a fácil adesão a clichês e padrões, que tocam a caricaturização e a tipologia escolar como modelo de organização do espaço social juvenil, e a promoção de uma nova forma de afeto igualitário de acordo um esquema psicopolítico narcisista. Neste esquema, o outro é sempre pequeno, semelhante ou rival, e permanece cristalizado no registro do imaginário: domínio fascinante do corpo, da forma e da imagem, e que, segundo Antonio Quinet (2012:11), faz com que o homem se julgue um "eu".

A percepção visual do corpo torna-se a base do processo de identificação, e é onde pulsões autoeróticas circulam. Neste circuito, conteúdos, pensamentos e intenções são projetados num outro que se localiza ora como um objeto de admiração, ora como um rival intruso; relação que baseia a experiência de outridade na semelhança, quando o "eu" e o "outro" lutam por um reconhecimento recíproco. Conforme pondera Quinet:

Trata-se de uma luta para ver quem tem mais prestígio que o outro, e para tal é necessário que um reconheça o outro. Nessa luta, descrita por Hegel como uma luta de "puro prestígio", na dialética do senhor e do escravo, há um desejo de reconhecimento de um pelo outro, que se transforma em uma luta mortal, pois eles entram na lógica do "ou eu ou você". Eis a luta travada no âmbito do narcisismo em que um quer ser reconhecido como um eu (ego) pelo outro. (10) 
Esta manutenção do registro imaginário especular nos modos de semiotização e subjetivação sociopolíticos é, por fim, o que caracteriza a dinâmica afetiva das relações teenagers tal como são representadas nos filmes de High School. A aprovação da multidão, a ovação na cantina da escola, na quadra de esportes ou no baile de formatura, e a perfeição alcançada diante do olhar do outro colocam o afeto da massa como única forma de encantamento de mundo possível.

\section{O CLUBE DOS CINCO E O TOPO DA TRANSFORMAÇÃO SUPERFICIAL}

Quando a noção de teenager integrou-se de uma vez por todas ao cotidiano americano a partir da década de 1950, as retratações desse novo modo de ser na cultura foram se adequando ao idealismo conservador das imagens dos subúrbios, que ora festejavam o consumismo e a inovação da juventude, como em comédias de situação televisivas (Father Knows Best, Leave it to Beaver, The Adventures of Ozzy na Harriet), ora se assombravam com a ameaça juvenil aos valores tradicionais, especialmente no cinema, com filmes como Juventude Transviada (Rebel without a cause), O selvagem (The Wilde One, 1953) e Sementes da violência (Blackboard Jungle, 1955).

Com o declínio do cinema clássico, durante esse mesmo período, houve o que se pode chamar de 'juvenilização' dos conteúdos fílmicos. A introdução dos teenpics (filmes adolescentes) na agenda dos grandes estúdios a partir dos anos 1950 tornou-se objeto de investigação de autores como Thomas Doherty (1988). Em seu livro Teenagers and Teenpics: The Junvenilization of American Movies in the 1950s, ele realiza um levantamento histórico desse gênero fílmico com foco na economia da indústria cinematográfica e repensa os teenpics em quatro sub-categorias: Rock'n Roll teenpics; Dangerous youth teenpics; Horror teenpics e finalmente os Clean teenpics.

Esta última sub-categoria nos interessa especialmente por ser representativa de filmes mais "escapistas, leves, alegres e românticos" (196), e por ter trazido o teenager para o centro da indústria de entretenimento, capturando a sua imagem para fora do lugar comum da rebeldia e delinquência como aconteceu aos primeiros filmes da década de 1950.

Ao configurarem-se, portanto, como um subgênero que se mobilizava em torno de temas confortáveis ao olhar como a beleza e a felicidade juvenil, estas imagens carregavam consigo a leveza do apolítico e do ideologicamente conveniente. Filmes populares que se passam na praia como Gidget (1959) foram 
marcantes para a proliferação do subgênero, que passava a existir para uma faixa etária basicamente adolescente.

Em Gidget acompanhamos a descoberta amorosa de uma adolescente que não se adéqua ao perfil de men hunter como se chamam suas amigas, e passa a se interessar por surfe e a conviver com os garotos da praia. Com enredos deste tipo começava-se a delinear, de forma discreta e pouco notada, a relação fetichista da imagem do entretenimento visual americano com a juventude, e com seu representante ideal, o teenager. $O$ adolescente não era mais estritamente um problema social a ser repensado e reajustado para o interior de um modelo social dominante, mas se tornava, ele mesmo, um modelo dominante: fisicalidade impecável, beleza e vitalidade.

No entanto, a adoração da adolescência no cinema atingiu um momento especialmente prolífico a partir da década de 1980, quando filmes como Picardias Estudantis (Fast Times at Ridgemont High, 1982) e a série Porky's (1982, $1983,1985)$, mais voltados para a fantasia sexual masculina da 'perda' da virgindade, tornaram-se hits e abriram espaço para o cenário do High School como lócus festejado para o estabelecimento de relações psicossociais.

Nestes filmes, a rebeldia não era vista como um problema, mas como um elemento comum aos plots, ou uma regra. A imagem do teenager era abertamente dissociada da noção óbvia de conformismo, talvez como única forma de conformá-lo, com relativo sucesso, aos moldes da sociedade da qual faziam parte, "oprimida" pela ostensividade dos imperativos do prazer e do consumo e movida segundo disposições subjetivas que desde então não mudariam mais: o cinismo e o narcisismo como marcas indissolúveis de seu comportamento.

Um filme revela-se quintessencial nesse sentido, e supera a sensorialidade machista de antecessores como Picardias Estudantis e Porky's, redimensionando o subgênero dos teenpics segundo uma discursividade cínica. $O$ clube dos cinco (The Breakfast Club, 1985) foi reconhecido como um "retrato" da geração teen dos anos 1980, por aparentemente descrever a angustia adolescente em tempos de sarcasmo e niilismo dominante.

Neste filme, a alteridade, o reconhecimento, a popularidade e a infâmia passaram a ser abordados como um problema sério do universo juvenil. O plot é tão didático quanto possível, acontece durante um sábado de detenção, quando cinco estudantes, que nunca foram amigos, são obrigados a passar o dia na escola e escrever um ensaio sobre a razão de estarem ali. Durante este dia, eles passam a se conhecer, discutem entre si, tentam se divertir e acabam 
em uma roda terapêutica em que comunicam uns aos outros, suas principais angustias e a razão de terem sido punidos com a detenção. Trata das relações entre cinco "arquétipos" do universo High School:

I. A princesa Claire Standish (Molly Ringwald): também conhecida como prom Queen (rainha do baile), prep (garota preparada para a faculdade), miss popularity (popular);

II. O rebelde John Bender (Judd Nelson), que também poder ser taxado como punk ou criminal (marginal).

III. O caso perdido Allison Reynolds (Ally Sheed): em inglês basket case, solitária, esquisita (weirdo), gótica;

IV. O atleta popular Andrew Clarck (Emílio Estevez): jock (tipo de esportista preconceituoso, que pratica bullying e só tem encontros com cheerleaders), também conhecido como sporto (alguém que acredita que é muito bom nos esportes) e

V. O cérebro Brian Johnson: o geek, o aluno nota 'A', o jerk (otário).

Enquanto o seu foco narrativo busca estabelecer as bases para uma crítica às formas de vida no High School americano e oitentista, por meio da projeção de uma mensagem final reparadora, visualmente o filme marca a consagração daquilo mesmo que critica, a padronização ou tipologia de um jardim platônico teenager por meio da fetichização da aparência como signo de prestígio e reconhecimento. Ali não há beleza na atividade intelectual, apenas solidão, estranheza e exclusão social. Não há efetividade perlocucionária na relação estabelecida entre o dizível e o visível. E esse torna-se um tipo de esquema didático para a organização libidinal ou gozo visual estabelecido junto a este tipo de imagem/narrativa.

Quando forçamos a nossa percepção a fim de entender por que $O$ clube dos cinco é um filme celebratório de uma fantasia eugênica não estamos de forma alguma nos referindo às formas de vida por ele retratadas - adolescentes que sofrem com as exigências de seus pares e da sociedade adulta - mas especificamente à estruturação cínica de seu desfecho, que se concretiza por meio de uma operação de pôr o outro em fetiche, ou seja, inseri-lo em um padrão pré-estabelecido, capaz de conformá-lo ao grupo como um sistema psicossocial idealizado.

A sensibilidade pop marca o início do filme. Enquanto os créditos são apresentados, podemos ouvir a música Don't you forget about me (Simple Minds), a 
explosão de uma citação de David Bowie ${ }^{3}$, como vidro estilhaçado, que resulta numa vista panorâmica da fachada da Shermer High School e uma sequência de imagens no interior da escola, que alternam entre signos de disciplina e rebelião, culminando com o primeiro diálogo do filme entre Claire, a miss popularity e seu pai, no interior de um BMW.
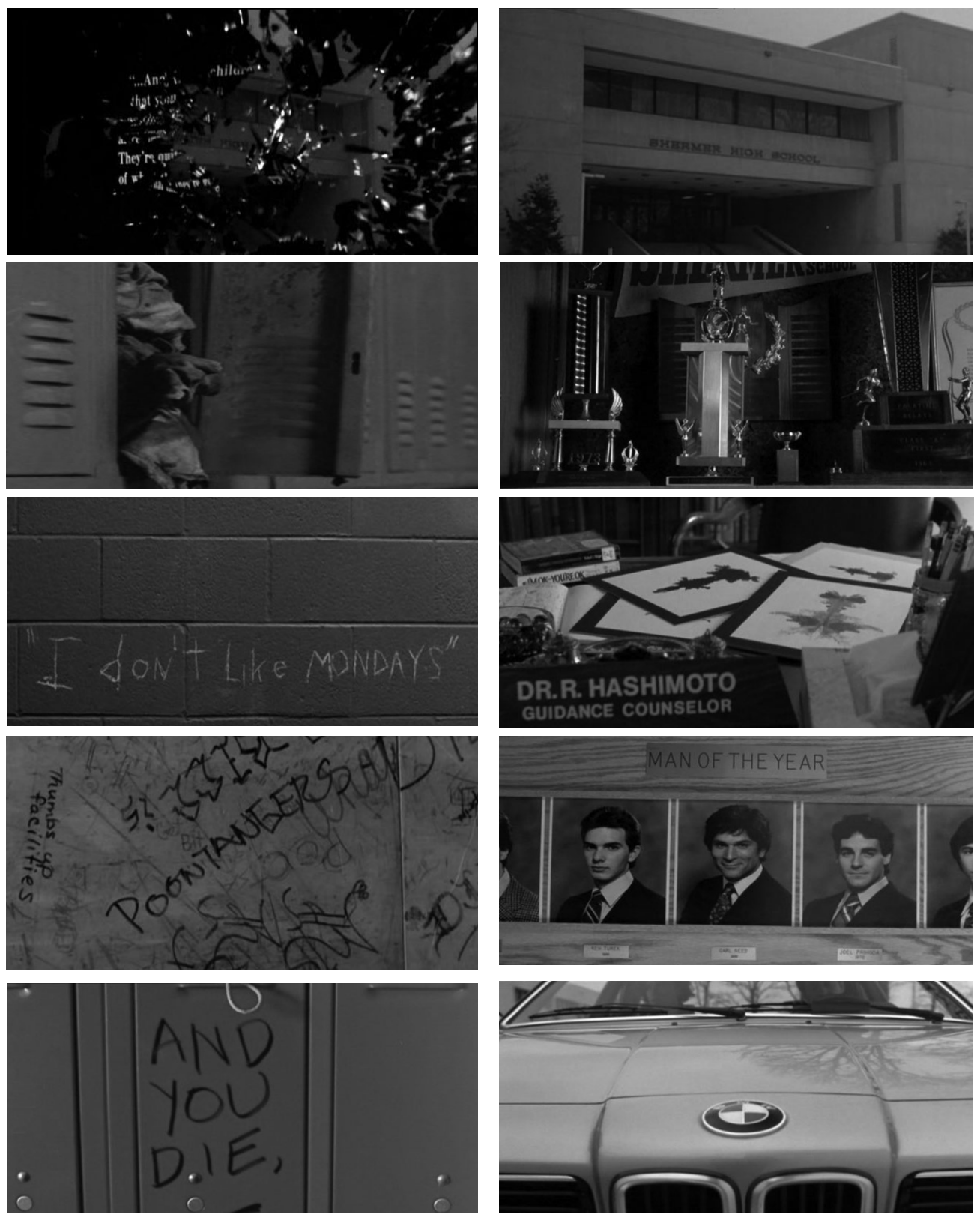

Figura 1: tensão visual entre norma, transgressão e status quo

Enquanto as imagens prosseguem pode-se ouvir em off a voz de Brian, o

3 "... and these children that you spit on as they try to change their worlds are immune to your consultations. They are quite aware of what they are going through..." 
nerd, que narra a sua dissertação sobre o porquê da detenção, ao apresentar os colegas como tipos padronizados do High School. Nessa sequência, entre os signos representacionais e não representacionais que se alternam (cenário, personagens e música) estabelece-se a partir de uma linguagem metonímica a aparente tensão em torno da qual o teenager surge como personagem central da cultura do entretenimento.

Sob esta visualidade pop jaz um fundo pático, no entanto: a insistência em se marcar visualmente os tipos escolares "clássicos" e a relação de dependência sempre-já estabelecida entre aparência e reconhecimento. A esquisita Allison senta-se ao fundo da sala enquanto os populares Claire e Andrew sentamse juntos na primeira fila.

A narrativa tenta desestabilizar esses padrões e os laços sociais são estabelecidos entre os personagens, de forma que, conscientemente, o discurso da tolerância e da diversidade faça superar o desejo pela tipologia que resiste na imagem. Embora Claire deixe claro que não será possível cumprimentar os outros estudantes no corredor da escola na segunda-feira, quando questionada por Brian, o desfecho do filme acaba sucumbindo ao imperativo do "final feliz" de forma a dissolver o sofrimento de indeterminação de seus personagens como norma escapista (e sintomática) do entretenimento comum aos teenpics.

Após euforizar a angustia do enquadramento psicossocial no High School americano - na sequência dramática em que cada um revela o motivo de estar ali - o filme é concluído a partir do tropo comum a todos os outros filmes do gênero: a transformação superficial e súbita de suas personagens. De forma irônica, as coisas parecem boas ou más apenas por efeito de uma operação narrativa de redenção instantânea. Recurso geralmente comprometido com um efeito moralizante, oportuno às demandas de uma sensibilidade terapêutica.

Dois casais "imprevisíveis" são formados ao final do filme. Primeiro: Claire, a patricinha, e John, o rebelde, que sucumbem à reparação da "insuperável" diferença social. E o segundo, que segue a fórmula do culto da fantasia normótica comum aos filmes de High School: Allison deixa suas roupas pretas e seu jeito gótico, é maquiada por Claire, e o atleta Andrew passa a enxergá-la, apaixonando-se subitamente. A weirdo torna-se bela e desejável quando se conforma ao estereótipo de prom Queen. Situação que substitui a cena clássica dos filmes de High School em que, por meio de uma transformação superficial que antecede o baile de formatura a garota inteligente sucumbe às demandas da beleza física como forma de aquisição de reconhecimento. 
Brian, o inteligente, fica só. A ele resta o anonimato e a solidão da devoção intelectual e da seriedade da idéia. Claire, que antes havia afirmado que não seria possível cumprimentá-lo pelos corredores na segunda-feira, o convence a escrever a dissertação em nome de todos, porque ele é o mais capacitado para isso. Magro, fraco e abobalhado, o arquétipo da inteligência é visualmente dessensualizado.

Esses desfechos paliativos apontam finalmente para um comprometimento sintomático da "racionalidade dramática", no sentido em que Jacques Rancière (2009:21) expõe em $O$ inconsciente estético. Não há porque um teenpic, submetido à lógica do entretenimento e ao domínio de suas fantasias oferecer "a verdade que reclama" e dar ouvidos a sua palavra "mal encoberta". O pathos do saber eugênico é excluído da performance, ele se torna um "melhor não saber": melhor não saber que a beleza é redentora, que o intelectualismo é para os fracos, e que a potência da imagem teenager está comprometida por uma normose estética devastadora.

Embora não se conclua como a maioria dos filmes de High School que evidenciam a transformação superficial de suas personagens na cena apoteótica de reconhecimento/infâmia do baile de formatura (ou qualquer substitutivo para a reunião grupal), O clube dos cinco deve ser entendido como quintessencial porque estabelece as matizes da representação e da identidade como categorias antecipativas da dramaticidade/entretenimento, por meio de uma denegação conveniente e de um imperativo da tolerância. Ele é um antecessor "sério" de um conjunto de filmes e seriados televisivos que transformarão o High School em fetiche do entretenimento. Mas a sua seriedade, com observamos a partir de seu desfecho mágico e obrigatório, torna-se o sintoma maior de sua performatividade cínica.

\section{SELETIVIDADE TEENAGER}

A seletividade discreta exercida ou amortecida por meio do tropo da transformação superficial nos teenpics atua com uma potência insuspeita e residual do desejo eugênico. Essa volatilidade das identidades leva para o centro da imagem o protótipo do sujeito narcísico das sociedades de consumo, sobre o qual Zizek tem discorrido em suas obras principais: "sujeito que só conhece as 'regras do jogo' social que lhe permitem manipular os outros, ao mesmo tempo em que se mantém distante de um compromisso sério". (1992:71)

Mas essa sutil operação egóica na superfície da aparência ou semblância, 
clichê em torno do qual as expectativas se mobilizam ao longo de uma diversidade de tramas, pode também ser entendida como uma fantasia seletiva muito suave. No filme Gatinhas e Gatões (Sixteen Candles) percebemos a seletividade como um traço humorado, porém imperativo do universo teenager.

O percurso do desejo no filme é mobilizado por um senso purista de comunidade em detrimento da estranheza risível de tudo aquilo que não alcança a fisicalidade anglo-saxônica idealizada: o estudante japonês retratado como débil mental, o ítalo-americano cuja família parece nociva aos costumes americanos civilizados, a garota que usa aparelho e que sofre para usar o bebedouro da escola, a retratação dos velhos como sujeitos insuportáveis, e especialmente os nerds, perseguidores obcecados da protagonista Samantha Baker (Molly Ringwald). A trama se inicia com Samantha enfrentando o dia mais "trágico" de sua vida, quando seus pais esqueceram-se da data de seu aniversário de dezesseis anos. Ela cultiva uma paixão secreta por Jake Ryan (Michael Schoeffling), o garoto mais bonito da escola, enquanto furta-se às investidas constantes de Geek (Antony Michael Hall) o magricela obcecado pela ideia de perder a virgindade.

A comicidade do filme se constitui a partir da tensão gerada pela constante ameaça desses elementos feios, defeituosos e decrépitos à imagem ideal do teenager integralmente afixada à fantasia da normalidade burguesa, a qual a protagonista reluta em preservar. O triunfo de Samantha é alcançado quando ela finalmente celebra os seus dezesseis anos ao lado de Jake ao fim do filme, e quando Geek, por sua vez, perde a virgindade com a garota mais popular da escola, a ex-namorada de Jake. A auto-realização é alcançada por ambos quando realizam a convenção das fantasias reacionárias clássica: o sexo para o homem e o amor para a mulher, ao lado de seus pares, baluartes da beleza física e da popularidade.

Os filmes de John Hughes nos anos 1980 reinventaram os teenpics sob o impacto inovador do sarcasmo e do niilismo como recursos dramático e cômico relativamente originais. Mas a fórmula logo foi absorvida pela indústria do entretenimento. $O$ desencantamento de uma geração e mais ainda, as formas falsamente esclarecidas de lidar com ele, nos termos de uma linguagem audiovisual, tornaram-se referenciais sensíveis para a proliferação de produtos sobre (e voltados para) este público. O fascínio gerado por esse jardim platônico idealizado pelo imaginário teen revela-se por meio da dimensão seletiva da imagem, a qual somente alguns são dignos de habitar, como um tipo fantasioso de sociodarwinismo cool.

Tomemos o filme Meninas Malvadas (Mean Girls, 2004) enquanto modelo 
atualizado de exaltação desta seletividade pelo entretenimento visual.

Meninas Malvadas conta a história de Cady Heron (Lindsay Lohan) adolescente que chega da África para estudar em um High School no subúrbio de Chicago. Desconhecida por todos, mas com boa aparência, logo ela chama a atenção das Plastic, garotas populares e ricas da escola, que a convidam para participar do grupo. A sua trajetória segue do ostracismo, quando era amiga de dois homossexuais, para a celebridade absoluta vivida ao lado das prom queens. A sua redenção acontece quando ela aprende "uma lição" e se arrepende dos danos causados às pessoas mais próximas e a quem mais amava em nome da popularidade.

O status social no espaço da escola é experimentado por Cady quando ela se integra ao grupo das Plastic. Quando se descobre errada e arrependida por seu atos, é punida com a obrigação de participar de uma gincana de matemática com os nerds da escola. No embate com a nerd de aparelho nos dentes e "sobrancelhas mal-feitas", não consegue se concentrar na solução da equação porque a feiura da rival a incomoda. Depois de sofrer com o rechaço social por ter se tornado tão má quanto as Plastic é coroada a rainha do baile, reconquistando a fama e a notoriedade, enquanto a menina mais bela e cruel da escola, Regina George (Rachel McAdams), termina usando aparelhos de correção de postura, em pleno de baile de formatura, decorrentes de um atropelamento que todos acreditam ter sido causado por Cady. A fisicalidade deficiente no momento apoteótico do baile parece ser o castigo maior e a única forma de desvirtuar Regina de sua imagem fascinante.

A técnica perversa de enunciação do filme, e que é parte indissociável do seu elã como uma peça do entretenimento visual contemporâneo, funciona segundo a captura irresistível dos sentidos pelo vigor físico, por uma perspectiva belicosa do feminino, pelo amor ao poder da aparência, pela felicidade do consumismo, e pelo enfeiamento/desprazer da vida intelectual.

Como vemos de relance em todos esses filmes, o imaginário teenager também aposta na ideia segundo a qual consumismo e aparência são articulados como signos associados à seleção e evolução de padrões fenotípicos. No High School midiático podemos ver mais claramente a postura ético-estética denegada da imagem no entretenimento mainstream sobre quem é digno de habitá-la e quem não é. É o que observaremos na próxima seção ao evidenciarmos que a estetização do consumismo como acontece em uma diversidade de plots atualiza um tipo de imaginário sociodarwinista nas retratações dos teenagers. 


\section{CONSUMISMO TEEN COMO AGÊNCIA DA SELEÇÃo}

Superfluidade, semblância e anti-intelectualismo são os predicativos para o prazer visual em uma diversidade de teenpics. Nessa paisagem midiática composta por seriados televisivos e filmes podemos notar que tipos colegiais recorrentes atuam como padrões manuseados que mantém uma política da visualidade sobre quem é digno de reconhecimento no plano do conteúdo e especialmente quem é capaz de habitar/protagonizar as imagens da juventude no plano de expressão. O quadro da imagem pode revelar-se nesse sentido como um espaço inacessível e purista de visualidade.

Uma característica importante dessa imagem refere-se à posse e exibição de bens materiais e ornamentos capazes de realçar ou indicar aptidóes físicas de seus personagens. A noção de que privilégio moral pode estar associado à capacidade de consumo e à fisicalidade torna-se um meio para percebemos como prossegue no imaginário midiático uma fantasia eugênica que circula como um traço estético inconsciente da modernidade.

A imagem do teenager tem um potencial especial nesse sentido, pois é capaz de fazer sobreviver o sentimento de comunidade vibrante, monotemático e purista, fundamental ao mesmo tempo às sensibilidades fascistas e ao processo de consolidação identitária adolescente, por meio da celebração de sociedades ego-idealizadas, narcísicas, individualistas, e potencialmente seletivas, como as que são retratadas no universo bem humorado ou melodramático dos High School. Um tipo de política estética desterritorializada cuja pré-história remonta às reverberações classistas e racistas projetada por crenças científicas profundamente ideológicas como o sociodarwinismo e a eugenia no século XIX.

A partir de fins dos anos 1980, especialmente, o consumismo tornou-se um imperativo categórico ainda mais evidente na retratação de uma unidade comunitária teenager. A beleza e a cultura pop associadas ao consumismo terminavam por associar o desejo da imagem teenager ao circuito da satisfação irrestrita, por meio do agenciamento visual dos excessos ostensivos de uma cultura altamente material. No interior de imagens coloridas, cômicas e descompromissadas, um novo tipo de esquema de sobrevivência e reconhecimento confirmava-se como um agente visual da seletividade midiática.

Esse processo inconsciente de 'sociodarwinização' sensível da juventude em nome de uma estética fluída do entretenimento torna este espaço de diversão um lócus para o exercício de sensibilidades que valorizam a associação da 
noção de sucesso existencial à luta pelo reconhecimento baseado na aparência física e em seus ornamentos. Dessa forma, uma elite fantástica e despolitizada passou a atrair o olhar e os sentidos do jovem espectador.

Na década de 1990 o seriado televisivo Barrados no Baile (Beverly Hills 90210) tornou-se um grande sucesso pelo canal FOX ao explorar as dificuldades dos irmãos Brendon e Brenda, recém chegados a Beverly Hills para se integrar ao High School da cidade. Este fenômeno massivo do entretenimento fundou o que poderíamos entender como um tropo da inclusão do teenager de outro grupo ou classe social por meio de um esquema de sedução material. No caso de Barrados no Baile, Brendon e Brenda, originalmente de Minneapolis, passam por um processo de aceitação ao longo da primeira temporada, de forma a reformular o pathos pela dignidade de acordo não somente com os imperativos da aparência e da imagem de si, mas também em relação a uma certa noção de gozo da riqueza na imagem.
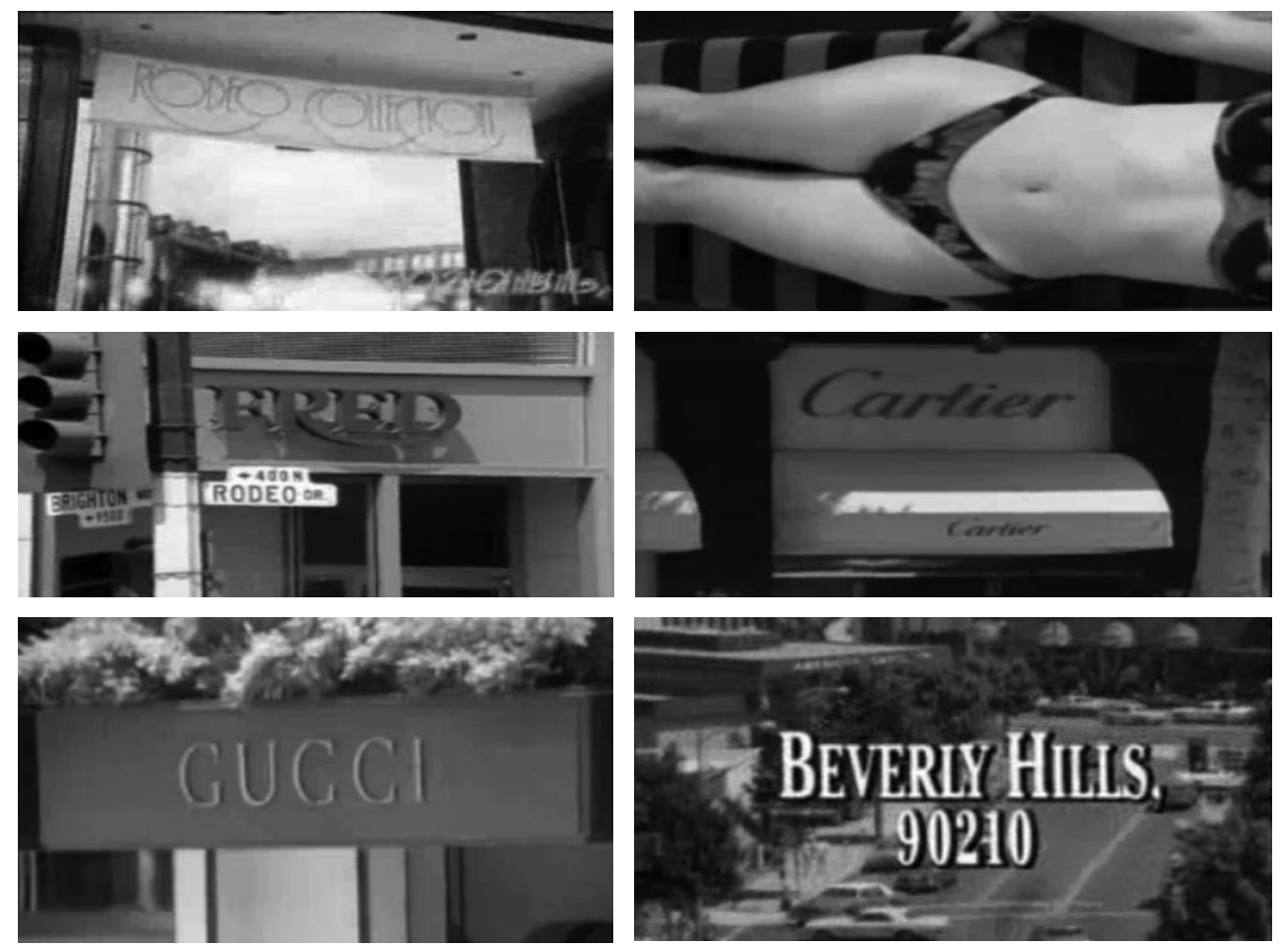

Figura 2: Stills da sequência inicial dos créditos de abertura de Barrados no Baile ( $1^{\mathrm{a}}$ temporada) - grandes marcas entre imagens de Beverly Hills

Os enredos semanais ao longo dos dez anos da série - que retratou a passagem da adolescência para a fase adulta de seus personagens - costumavam tocar em temas como convites para festas, consumo de álcool e drogas, conflitos com os pais, namoro, traição, aborto, boatos e popularidade. $O$ cast era for- 
mado por jovens brancos, saudáveis e especialmente bonitos. Temáticas como AIDS, homossexualidade e preconceito racial aconteciam de forma excêntrica aos personagens veteranos da série, de forma a evidenciar quão impenetrável e fechado era o sentido de comunidade entre eles.

O espaço impenetrável de privilegiados sociobiológicos é um recurso dramático também em outro hit teenager da década de 2000: Gossip Girl. Neste seriado, que narra o cotidiano de adolescentes milionários de Manhattan e o processo de inserção dos irmãos Dan e Jennie Humphrey diretamente do Brooklyn numa escola elitizada de Upper East Side, podemos observar a captura total da imagem por uma lógica do fetiche do consumo.

A noção de dignidade baseada na aparência física e na ostensividade de bens materiais - do estilo das roupas aos gadgets tecnológicos - atua segundo uma gramática exibicionista dos privilégios do poder, e especialmente de tudo o que é incapaz de alcançá-lo. O afeto belicoso e a violência simbólica são estetizados sem precedentes no universo do High School, sensibilizando a noção de cool por meio de um tipo de garimpagem seletiva entre quem é capaz de "aguentar" e "lidar" com as pressões desse universo sociossimbólico e quem não é.

Os adolescentes retratados na série vivem entre armações e armadilhas feitas uns pelos outros e por uma 'fofoqueira' virtual de forma a ascender disputas em que infâmia e dignidade estão sempre em risco, e que são geralmente resolvidas por meio do recurso de uma ostensividade visual: grandes festas com convidados especiais, convites para desfiles de modas de Nova lorque, presentes caros e exibição de riqueza. Os desfechos moralizantes apostam mais uma vez no recurso da transformação superficial e no auto-sacrifício em nome da unidade e impenetrabilidade do grupo. Seus integrantes são o centro das atenções também no plano do conteúdo, porque geralmente são as principais vítimas/celebridades atingidas pela gossip girl.

A fantasia da integração social por meio da captura de um estilo de vida glamouroso possui o contraponto dramático de uma juventude cujas intrigas acontecem em acordo com o excesso ou a escassez de recursos materiais. $O$ sofrimento da insatisfação representa um imperativo categórico que torna a imagem ainda mais sedutora, fetichizada, e por fim, agenciadora do desejo como um negativo, baseado mais uma vez no circuito do significante da falta e da insatisfação capitalística. O sadismo/masoquismo superegóico funciona, como em nenhuma retratação teenager, submetido aos imperativos libidinais da sociedade de consumo, capturando o olhar de acordo com as tensões e ambivalências 
de um regime de visualidade oprimido/fascinado pelo excesso de poder.

Em Gossip Girl a branquitude e a heteronormatividade são também elementos essenciais ao sentido de comunidade teenager entre seus pares. A tentativa da imagem de lidar com a 'ainda' outridade da raça e da sexualidade acontece mais uma vez a partir da lógica artificial do paradigma da tolerância, ou seja, da necessidade de aturar (normalizar) o outro enquanto elemento inevitável à coesão do grupo. Essas outridades, apresentadas como acessórias ou com participação limitada nos plots evidenciam o compromisso de Gossip Girl de atuar em acordo com os códigos do correcionismo político que se aplica ao entretenimento mainstream como um todo. Mais uma vez o uso de drogas, o sexo promíscuo, a crueldade com os pares e os distúrbios alimentares são abordados com vistas a um tipo de gozo visual que deverá ser refreado por algum tipo autoridade parental - a "lição aprendida" a cada desfecho - de forma a conformar a imagem a um padrão sintomático do entretenimento. Transgressão e norma convivem a partir dessa duplicidade performativa. De forma análoga, a fantasia fascista da seleção pode coexistir com a falsa intenção de se "varrê-la para baixo do tapete".

O desprendimento da imagem em relação ao que tenta comunicar no plano do conteúdo - o pesadelo e o prazer que são viver na classe rica de Manhattan como sugere a série de livros de Cecile Von Ziegeser a qual inspirou o seriado - a torna impactante visualmente, e eleva a um nível dramático a relação intrínseca entre entretenimento e consumo que orienta a sensibilidade teenager como produto rendido à seletividade da cultura midiática. O seriado opera por meio de uma comodificação total da imagem. Imagem tornada ela toda fetiche, e que inspira a noção de reconhecimento social baseado na fantasmagoria da grandes marcas, cheias de personalidade, e que conforma o objeto consumido a uma idealidade social exclusivista.

O que os jovens vestem, veem e usam tornam-se agentes visuais reguladores de um espaço imagético privilegiado, classista e fantasioso, o qual apenas o belo, o branco, o heterossexual e o saudável são capazes de habitar, como se pode constatar abertamente no plano de expressão, visualmente curvado a um pathos higienista. Afinal como afirma Vladimir Safatle (2010:124): "a imagem-fetiche é sempre modo de colonização do que não é imediatamente imagem”. Ela está articulada sempre a um desejo incomodo, que só é passível de funcionar pelo viés do 'feitiço' do artifício.

Em suma, a imagem desses teenagers apenas 'faz de conta' que esconde 
o desejo eugênico de excluir os fracos, feios e pobres, seja de Upper East Side, Beverly Hills ou da paisagem midiática comprometida pelo amor ao poder.

\section{CONSIDERAÇÕES FINAIS}

O High School midiático pode se tornar o espaço privilegiado para o cultivo de uma forma imaginária de eugenia, para a sua manutenção na ordem do cotidiano "a-político" do entretenimento. De acordo com a linguagem ou o esquema visual de alguns produtos, o "estar dentro" da imagem confere ao teenager um tipo de privilégio não apenas sociopolítico, mas sociobiológico. A cara noção de reconhecimento, portanto, não é para todos. Ser popular, ou seja, existir para um agigantamento do ego, do desejo de impor uma imagem de si ao outro especular é regulada segundo a lógica de uma estética excludente. A luta pelo bastião da popularidade é antes uma luta ou um jogo de sedução entre o mais forte e belo em relação ao mais fraco e feio. Especialmente à sua "salvação" da obscuridade por meio de uma transformação superficial que flerta terminantemente com a ideia de um melhoramento biofísico.

\section{REFERÊNCIAS}

ARENDT, Hannah. A vida do espírito. Rio de Janeiro: Civilização Brasileira, 2010.

DOHERTY, Thomas. Teenagers and teenpics: the juvenalization of american movies in the 1950s. Boston: Unwin Hyman, 1988.

QUINET, Antonio. Os outros em Lacan. Rio de Janeiro: Jorge Zahar Editor, 2012.

PIETROFORTE, Antonio Vicente. Semiótica visual: os percursos do olhar. São Paulo: Contexto, 2004.

RANCIÈRE, Jacques. O inconsciente estético. São Paulo: Editora 34, 2009.

SAFATLE, Vladimir. Cinismo e falência da crítica. São Paulo: Boitempo, 2008.

SAVAGE, Jon. A criação da juventude: como o conceito de teenage revolucionou o século XX. Rio de Janeiro: Editora Rocco, 2007.

SLOTERDIJK, Peter. 0 desprezo das massas: ensaio sobre lutas culturais na sociedade moderna. São Paulo: Estação Liberdade, 2002.

ZIZEK, Slavoj. Eles não sabem o que fazem: o sublime objeto da ideologia. Rio de Janeiro: Jorge Zahar Editor, 1992. 
RECEBIDO EM: 12/10/12

ACEITO PARA PUBLICAÇÃO: 01/11/12

\section{Frederico Antonio Feitoza}

Doutorando pelo Programa de Pós-Graduação em Comunicação da Universidade Federal de Pernambuco, onde desenvolve pesquisa sobre Estética Fascista e Psicanálise em imagens de entretenimento. Mestre em Comunicação pela mesma instituição. 